\title{
Rádio Comunitária e povos indígenas: entraves e potencialidades para pluralidade de vozes
}

MESQUITA, Giovana Borges ${ }^{1}$

\begin{abstract}
Resumo
O artigo busca analisar os principais entraves para a instalação e funcionamento de uma rádio comunitária numa área indígena situada em Pernambuco, estado com a quarta maior população indígena do Brasil, composta por mais de 47 mil pessoas, que habitam a região Agreste e o Sertão. Ao mesmo tempo, o trabalho propõe uma reflexão sobre como as comunidades indígenas, na maioria das vezes criminalizadas pela mídia hegemônica, podem tentar caminhos para ter acesso a comunicação, como um direito humano, assumindo a rádio comunitária como espaço para o exercício da cidadania. O trabalho é um relato da experiência da "gestação", ao longo do último ano (2017-2018) do Programa Institucional de Bolsas de Iniciação à Docência para a Diversidade (Pibid Diversidade), de uma rádio comunitária na web, que como destaca Peruzzo (2010), é um espaço propício ao fornecimento de informações e de discussão dos assuntos de interesse local, além de funcionar difundindo a produção cultural dos grupos onde está inserida e em seus entornos.
\end{abstract}

Rádio Comunitária. Direito à Comunicação. Pibid Diversidade.

Community Radio and indigenous people: obstacles

and pontecialities for the pluralities of voices

\section{Abstract}

This article analyzes the main obstacles to the installation and operation of a community radio station in an indigenous area located in Pernambuco, Brazil's state with the fourth largest indigenous population, composed by more than 47 thousand people living in the Agreste and Sertão regions. At the same time, the work proposes a reflection on how indigenous communities, most often criminalized by the hegemonic media, can try pathways to have communication access, as a human right, by assuming community radio station as a space for citizenship exercise. The

\footnotetext{
${ }^{1}$ Professora do Programa de Pós-Graduação e do curso de Comunicação da Universidade Federal de Pernambuco. Coordena o Grupo de Pesquisa Dinâmicas do Jornalismo e é integrante do Grupo Jornalismo e Contemporaneidade. Fez parte do Programa Institucional de Bolsas de Iniciação à Docência para a Diversidade - Pibid Diversidade na condição de Coordenadora de Área do subprojeto Bem Viver e Tecnologias, vinculado ao Povo Truká, de maio de 2017 a março de 2018. Email: giovanamesquita@yahoo.com.br
} 
work is an account of the "gestation" experience, through the last year (2017-2018) of the Institutional Program of Teaching Initiatives for Diversity (Pibid Diversity), of a community radio station on web, as Peruzzo (2010) points out, is a space conducive to providing information and local interest issues discussion, working as well to disseminate the groups cultural production where it is inserted and in its surroundings.

Community Radio Station. Communication Right. Pibid Diversidade.

\section{Introdução}

O rádio como um meio de comunicação faz parte do cotidiano de grande parte da população mundial. Dos meios de comunicação de massa o rádio é o mais privilegiado, por suas características intrínsecas, dentre elas, segundo Ortriwano (1985), a linguagem oral, a penetração, a mobilidade, o baixo custo, o imediatismo, a instantaneidade, a sensorialidade e a autonomia.

Barbosa (2003) acrescenta a essas características a intimidade que o rádio tem de falar para cada indivíduo, o regionalismo, a simplicidade do veículo, sua função social e comunitária, sendo um agente de informação e formação do coletivo. Logo, "desde a sua gênese vem se firmando como um serviço de utilidade pública, o qual exerce uma comunicação que em muito contribui para a história da humanidade" (BARBOSA, 2003, p. 49).

No Brasil, o serviço de radiodifusão atualmente é dividido em rádios comunitárias, educativas e comerciais. Cada uma com um papel claro e objetivos específicos para a população. Na prática, porém, nem sempre as finalidades dessas rádios são cumpridas por quem detém suas concessões.

Uma rádio comunitária, como o próprio nome diz, deve atender a comunidades e só deve ser operada por associação comunitária sem fins lucrativos. Como observa Peruzzo (2010, p.3) há quatro modalidades de rádio comunitária:

a) Rádios comunitárias legalmente constituídas- são rádios lideradas por organizações comunitárias locais e destinadas a atender pequenas áreas geográficas urbanas e rurais. Transmitem em frequência modulada ( $F M)$ de baixa potência. São regidas pela lei 9.612/1998, regulamentada pelo decreto $2.615 / 1998$, a qual prevê seu funcionamento somente em nome de associações comunitárias ou fundações. b) Rádios livres comunitárias - são emissoras que se assemelham as da modalidade anterior, mas com a diferença de que não possuem a autorização para funcionar. São, de fato, rádios livres de caráter comunitarista, as quais os setores conservadores chamam de "piratas" ou "clandestinas". Elas não se consideram piratas porque não visam lucro, nem clandestinas, pois não escondem seus endereços nem as frequências através das quais difundem seus 
conteúdos. c) Rádio de alto-falante - essa modalidade também é conhecida como rádio-poste ou rádio-corneta. São pequenos sistemas sonoros de "rádio popular" (rádio do povo) que transmitem suas mensagens através de bocas de alto-falantes ou de caixas reprodutoras/amplificadoras de sons. Rádios virtuais comunitárias difundem suas mensagens somente pela Internet, portanto só existem no ciberespaço. São ligadas a grupos ou comunidades constituídas a partir da afinidade de interesses e/ou de vivências de problemáticas em comum, tais como os de fundo linguístico, étnico, relações de gênero etc.

Há registros da existência das rádios comunitárias ainda nos anos de 1950, mas seu apogeu ocorre na década de 1980. Trata-se de um tipo especial de "rádio" desenvolvido por movimentos sociais e associações comunitárias, além de igrejas, especialmente a Católica, e até mesmo isoladamente por comunicadores populares ativistas, com finalidades informativas, mobilizadoras e educativas para fazer frente ao impedimento legal de uso do espectro radiofônico oficial por parte do cidadão e das comunidades.

O presente artigo busca analisar os principais entraves para a instalação e funcionamento de uma rádio comunitária numa área indígena situada em Pernambuco, estado com a quarta maior população indígena do Brasil, composta por mais de 47 mil pessoas, que habitam a região Agreste e o Sertão. Ao mesmo tempo, o trabalho propõe uma reflexão sobre como as comunidades indígenas, na maioria das vezes criminalizadas pela mídia hegemônica, podem tentar caminhos para ter acesso a comunicação, como um direito humano, assumindo a rádio comunitária como espaço para o exercício da cidadania.

O trabalho é um relato da experiência da "gestação", ao longo do último ano (2017-2018) do Programa Institucional de Bolsas de Iniciação à Docência para a Diversidade (Pibid Diversidade), de uma rádio comunitária na web que, como destaca Peruzzo (2010), é um espaço propício ao fornecimento de informações e de discussão dos assuntos de interesse local, além de funcionar difundindo a produção cultural dos grupos onde está inserida e em seus entornos (PERUZZO, 2010).

Peruzzo (2010) ainda ressalta a importância desses espaços como "escola" para a educação informal em comunicação, na medida que possibilitam os envolvidos serem incluídos em "lutas" para que comunidades de contextos populares conquistem o direito à comunicação e exercitem a liberdade de expressão.

\section{Sobre o Pibid Diversidade}

O Programa Institucional de Bolsas de Iniciação à Docência para a Diversidade (Pibid Diversidade) foi iniciado no ano de 2011 e desenvolvido em Caruaru (PE), no Centro Acadêmico do Agreste da Universidade Federal de Pernambuco, até março de 2018. 
Vinculado a Pró-Reitoria Acadêmica (Proacad), o Pibid Diversidade representou, ao longo desse tempo, uma fonte de diálogo entre a Educação Básica, a Universidade $\mathrm{e}$ as comunidades indígenas de Pernambuco. As ações extensionistas vinculadas a este Programa, segundo Silva \& Silva (2015, p.150), "têm diferentes acentos na relação socioeducativa, desencadeando um conjunto de atividades que evidenciam o fazer escolar e a formação para a vida".

Silva \& Silva (2015, p. 150) evidenciam o diálogo aprendente e paritário das ações desencadeadas pelos sujeitos participantes do Programa que:

Se constituíram num acervo de informações que aproximaram os saberes mobilizados pelas instituições de Ensino, da Educação Básica e de Ensino Superior, dos saberes advindos dos Povos Indígenas, promovendo alcances decoloniais com a participação de docentes/pesquisadores nacionais e Latino-Americanos.

Dentro do Pibid Diversidade foram pensados sete subprojetos de intervenção: Saberes Tradicionais; Língua, Leitura e Produção de Texto; Arte Indígena; Processos Próprios de Ensino e Aprendizagem; Gestão da Educação Escolar Indígena; Educação Inclusiva; Bem Viver e Tecnologias.

A intenção era que os sete subprojetos de intervenção reunissem diferentes estratégias de ensino e aprendizagem, em uma busca de contribuir para a articulação "Comunidade-Universidade", unindo os saberes próprios dos povos indígenas aos aspectos teórico-práticos exigidos no processo de formação e na atuação dos licenciandos na Educação Básica.

Buscou-se com os subprojetos fomentar experiências que permeassem o contexto da educação escolar indígena em relação à valorização e respeito aos saberes tradicionais. Seja valorizando e mantendo a sociodiversidade indígena, seja implementando a elaboração de materiais didático-pedagógicos que evidenciassem e valorizassem a diferença dos saberes tradicionais da população indígena.

\section{O subprojeto Bem Viver}

O Pibid Diversidade contempla a participação de 126 universitários/as do curso de Licenciatura Intercultural Indígena, que fazem parte de 11 povos indígenas pernambucanos (Atikum, Entre Serras, Fulni-ô, Kapinawá, Kambiwá, Pankararu, Pankará, Pipipã, Tuxá, Truká e Xukuru), distribuídos em 15 municípios do Sertão e do Agreste do Estado.

Com o subprojeto do Bem Viver e Tecnologias pretendeu-se refletir a 
importância dos valores e vivências dos povos indígenas, especificamente no que diz respeito a forma de vida diferenciada do "mal viver" da sociedade ocidental, visando contribuir numa educação escolar indígena própria a cultura e as formas de vida e de saberes desses povos.

Assim, a articulação entre as diferentes áreas do conhecimento e a integração dos subprojetos permitiu outros formatos relacionais, outros modos de fazer a educação básica e, sobremaneira, de construir novas identidades para o processo formativo do ensino superior à medida que os participantes revisitaram seus trajetos de vida e formação, dando-lhes outras interpretações de alcance afetivo e sociocultural.

Essa articulação entre as diferentes áreas do conhecimento possibilitada pelo Pibid permitiu também pensar no funcionamento de uma rádio web, criada e mantida pela comunidade dos Truká, que pudesse fazer jus ao nome de comunitária, como destaca Peruzzo (2007, p. 69):

\begin{abstract}
A rádio comunitária que faz jus a este nome é facilmente reconhecida pelo trabalho que desenvolve. Ou seja, transmite uma programação de interesse social vinculada à realidade local, não tem fins lucrativos, contribui para ampliar a cidadania, democratizar a informação, melhorar a educação informal e o nível cultural dos receptores sobre temas diretamente relacionados às suas vidas. $A$ emissora radiofônica comunitária permite ainda a participação ativa e autônoma das pessoas residentes na localidade e de representantes de movimentos sociais e de outras formas de organização coletiva na programação, nos processos de criação, [e quiçá] no planejamento e na gestão da emissora. Enfim, se baseia em princípios da comunicação libertadora que tem como norte a ampliação da cidadania. Ela carrega, aperfeiçoa e recria o conhecimento gerado pela comunicação popular, comunitária e alternativa no contexto dos movimentos sociais na América Latina desde as últimas décadas do século $X X$.
\end{abstract}

\title{
3 O povo Truká
}

Descendente da Nação Kariri e Tapuia, o Povo Truká é dividido em quatro grupos étnicos: Povo Truká do Aldeamento da Assunção, habitantes do município de Cabrobó (PE), Povo Truká Tapera dos Aldeamentos da Missão de Santa Maria, residentes no Município de Orocó (PE), Povo Truká do Aldeamento de Sobradinho (BA) e Povo Truká Tupã do Aldeamento da Cidade de Paulo Afonso (BA). Os grupos sempre povoaram as ilhas e ilhotas às margens esquerda e direita de todo médio $\mathrm{e}$ sub-médio do Rio São Francisco. 
A base de sustentação alimentar do povo é a agricultura de subsistência (feijão, milho, mandioca, arroz, hortaliças, fruticultura e pesca artesanal). O manejo produtivo sempre foi desenvolvido de forma tradicional levando em consideração os costumes dos antepassados. Como manifestações culturais, o povo Truká ainda preserva seus cantos (Tuantes), dança (Toré), trabalhos de ciência (conversa com os encantados e ancestrais).

\title{
4 Rádio comunitária entre limites e desafios
}

As rádios comunitárias no Brasil são emissoras de caráter público, sem fins lucrativos, historicamente criadas e geridas, na maioria dos casos, coletivamente. Elas desempenham importante papel no processo de conscientização e mobilização social sobre questões relativas à vida de segmentos da população empobrecidos e discriminados socialmente (PERUZZO, 2010).

As rádios comunitárias são regulamentadas pela Lei 9.612/98, que as definem como:

\begin{abstract}
Um tipo especial de emissora de rádio $\mathrm{FM}$, de alcance limitado a, no máximo, $1 \mathrm{~km}$ a partir de sua antena transmissora, criada para proporcionar informação, cultura, entretenimento e lazer a pequenas comunidades. Trata-se de uma pequena estação de rádio, que dará condições à comunidade de ter um canal de comunicação inteiramente dedicado a ela, abrindo oportunidade para divulgação de suas ideias, manifestações culturais, tradições e hábitos sociais. [...] Deve divulgar a cultura, o convívio social e eventos locais; noticiar os acontecimentos comunitários e de utilidade pública; promover atividades educacionais e outras para a melhoria das condições de vida da população. [...] Não pode ter fins lucrativos, nem vínculos de qualquer tipo, tais como: partidos políticos, instituições religiosas etc (MANUAL DE ORIENTAÇÃO PARA RÁDIOS COMUNITÁRIAS, 2009).
\end{abstract}

Em geral, segundo Peruzzo (2010), a programação dessas rádios deveria ser de interesse público e estar a serviço dos grupos organizados e/ou das localidades nas quais se inserem, numa perspectiva de que esse tipo de conteúdo contribuísse para o desenvolvimento social. Mas o exercício da cidadania por meio da rádio se encontra ameaçado em função da apropriação privada por comerciantes, grupos religiosos e políticos de um espaço que deveria ser público.

Outra questão pertinente trazida por Torres (2012) é que se faz necessário às rádios comunitárias começarem a fazer algo diferente do que vem sendo feito até agora nas emissoras comerciais. Se elas não consideram essa questão acabam simplesmente não sendo necessárias, de acordo com o autor. 
Torres (2012) ressalta que as rádios comunitárias deveriam debater diferentes temas, respeitando sempre a diversidade cultural, e não tolerando qualquer tipo de ditadura, nem sequer a musical dos grandes estúdios de produção e gravação.

Já Nunes (2001) faz um alerta que o uso comercial ou político partidário dessas emissoras representa uma grave ameaça à legitimação desse espaço alternativo de expressão das classes populares. Segundo a autora, por meio da utilização de práticas clientelistas, associações comunitárias são forjadas para justificar a concessão de canais comunitários que acabam nas mãos de políticos e comerciantes, distorcendo assim o verdadeiro sentido de existência dessas emissoras. (NUNES, 2001).

Dessa forma, seriam consideradas comunitárias as rádios que asseguram a participação plural de amplos segmentos sociais de todos os matizes que compõem uma comunidade, entendida:

Como grupo social, agregado por interesses, vivências e/ou não de um espaço geográfico comum, que participam de forma organizada e decidem coletivamente os caminhos a serem trilhados pelo grupo, tendo voz ativa nos diferentes canais de participação necessários à estruturação da emissora, tais como vivências políticas, elaboração da programação, etc (NUNES, 2010, p. 73).

Mas como destaca Lacerda (2017, p.319), apesar das rádios comunitárias terem surgido "como sopros de esperança na democratização da comunicação, logo a legislação de RadCom frustraria as expectativas dos setores que lutaram pela criação do serviço". A Lei n. 9 9.612/98 que instituiu as rádios comunitárias, o Decreto n. . 2.615/98 que as regulamenta, e as sucessivas Portarias do Ministério das Comunicações (MC), compõem um conjunto normativo "que passa ao largo daquelas demandas de democratização" (LACERDA, 2017, p.319).

No caso dos indígenas, além de problemas comuns a outros setores, Lacerda (2017, p.319) ressalta ainda que eles têm na legislação de RadCom alguns obstáculos específicos:

O primeiro está na concepção voltada apenas para o espaço urbano, de pequenas comunidades de bairro, vila ou povoado, desconsiderando demandas étnicas - culturalmente diversas. $O$ segundo é o limitado alcance das transmissões, restrito à potência máxima de 25 watts de frequência modulada (Lei 9.612/98, art. 1.․, caput e $\S 1 .^{\circ}$ ) e cobertura limitada ao raio de um quilômetro em torno da antena transmissora (Decreto $n . \stackrel{\circ}{2.615 / 98}$, art. 6. ${ }^{\circ}$ ). O terceiro está na outorga do serviço apenas "a fundações e associações comunitárias" (Lei 9.612/98, art. 1. ${ }^{\circ}$, caput), formas organizativas estranhas àquelas que Ihes são próprias. O quarto obstáculo está na 
exigência do apoio por "entidades associativas e comunitárias legalmente constituídas na área pretendida para a prestação do serviço" (Lei n. ${ }^{\circ} 9.612 / 98$, inc. VI, $\S 2 .^{\circ}$, art. 9. ${ }^{\circ}$ ), sendo que entidades associativas externas não podem ter sede dentro das terras indígenas. O quinto obstáculo é a exigência de criação de um "conselho comunitário" (art. $8 .^{\circ}$ da Lei n. ${ }^{\circ}$ 9.612/98) composto por representantes de entidades locais, legalmente constituídas, desconsiderando as formas colegiadas próprias das comunidades e permitindo formas estranhas dentro de suas terras. O sexto e último é a exigência, em Portarias do $M C$, de assentimento prévio do Conselho de Defesa Nacional em caso de Faixa de Fronteira, o que atinge especialmente os indígenas.

Lacerda (2017) observa que em 2007 o Projeto de Lei (PL) № 2.490 propôs modificar a Lei 9.612/98, estendendo às comunidades indígenas o direito de prestarem o serviço. O PL propôs dispensar àquelas comunidades a exigência de associações ou fundações, mas manteve a baixa potência e alcance restrito.

De acordo com Lacerda (2017), o PL foi aprovado pelas Comissões e recebeu Emenda Substitutiva para estender o direito às comunidades quilombolas e áreas rurais, mas sem qualquer alteração na potência e cobertura. Apesar de pronto para subir ao Senado, o PL está paralisado desde 2010, devido a recurso do Deputado Milton Monti (PR/SP) para que seja apreciado no Plenário da Câmara. (LACERDA, 2017).

\section{Rádio comunitária e o povo Truká}

No ano de 2017 além de avançar na consecução dos objetivos do PibidDiversidade da UFPE/CAA, por meio do aprofundamento da qualificação docente dos bolsistas e o incentivo ao registro da história do povo, houve um investimento em discussões e aprofundamentos sobre a utilização da rádio comunitária como um caminho de democratização da comunicação.

Os docentes do Pibid Diversidade iniciaram o ano de 2017 participando de um seminário, com a coordenadora do Subprojeto Bem Viver e Tecnologias, que é professora do Curso de Comunicação da UFPE, no qual foi feita uma discussão sobre o atual cenário da comunicação marcado por transformações na esfera midiática, que permite a qualquer pessoa, além das empresas de comunicação, não só consumir, como produzir e distribuir informações sob qualquer formato em tempo real, para qualquer lugar do mundo, sem ter que movimentar grandes volumes financeiros, ou ter que pedir concessão a quem quer que seja (LEMOS \& LÉVY, 2010).

A discussão chamava a atenção para as possibilidades que grupos muitas 
vezes excluídos do processo midiático hegemônico passam a ter um cenário mais favorável, graças ao acesso a internet e às redes sociais. Esses grupos contam com uma maior possibilidade de produzir e distribuir informações, abordar assuntos que dominam, contando sobre a realidade em que vivem, os problemas que encontram, as novidades que interessam àquela comunidade.

Durante as discussões neste primeiro seminário, o grupo Truká compartilhou o desconforto sobre como os indígenas são representados na mídia hegemônica. Uma das lideranças explicou que mesmo a comunidade sendo produtora de frutas, a mídia insiste em passar a imagem de que os Trukás são "preguiçosos e desocupados". O discurso jornalístico unilateral da mídia hegemônica, em grande parte, é criminalizante referindo-se aos indígenas, por exemplo, como "invasores" de terras. São discursos com base em relatos somente de fontes oficiais, deixando de fora a versão dos indígenas, um tipo de visibilidade que reforça estigmas e preconceitos por parte da sociedade.

Depois de trazer essas questões, o grupo demonstrou o interesse na implantação de uma rádio comunitária na comunidade, e pediu que fosse realizado outro seminário, desta vez, para esclarecer quais eram os aspectos legais e técnicos para colocar em funcionamento uma rádio comunitária no ar e, dessa forma, gestar um processo de comunicação contra hegemônico, tendo os próprios indígenas como protagonistas.

No segundo seminário sobre comunicação, ocorrido no mês de junho de 2017, com a presença dos pibidianos do povo Truká houve diversas discussões sobre a importância de uma rádio comunitária voltada para o interesse público, estando a serviço dos grupos organizados e/ou das localidades nas quais se inserem, o que pode trazer uma contribuição para o desenvolvimento social da região. Ainda foi discutido como as rádios podem desempenhar importante papel no processo de conscientização e mobilização social sobre questões relativas à vida de diversos segmentos da população que às vezes sofrem com uma "invisibilidade" por parte da mídia convencional.

Também foi mostrada a importância de que a rádio fornecesse informações e discutisse assuntos de interesse local, difundindo a produção cultural (entre outras) e que fosse criada no contexto dos próprios grupos aos quais também destinam sua programação.

Outro ponto muito enfatizado foi sobre a importância de se lutar pela conquista do direito à comunicação e a apropriação das tecnologias que ajudam a viabilizá-lo. As reflexões também foram se aprofundando e se encaminharam para a possibilidade de criação de rádios nas escolas campo de estágio.

Os pibidianos interessados receberam da coordenação do subprojeto Bem Viver e Tecnologias, um material com informações técnicas e legais sobre como montar uma rádio na escola, e como desenvolver uma programação envolvendo os 
estudantes e professores para que a rádio fosse também um espaço de exercício prático das atividades realizadas em sala de aula, sobretudo, das atividades relacionadas as linguagens e que também fosse utilizada como um veículo de registro e de divulgação da história do povo.

Além dos seminários e de vários encontros nos quais foram discutidas as potencialidades e possibilidades de incorporação da rádio ao cotidiano dos pibidianos, aconteceu um treinamento prático no dia 19 de fevereiro de 2018 sobre técnicas de redação, produção, programação, locução, com a radialista caruaruense, Risoní Santos. Neste treinamento foram discutidas ainda estratégias de visibilidade em redes sociais.

A ideia da coordenação do subprojeto Bem Viver e Tecnologias era mostrar que a rádio, comunitária ou escolar, possibilitava ao povo Truká, dentre outras coisas: a construção de um discurso plural da comunidade, buscando contribuir na ampliação dos direitos e deveres de cidadania; resgatar a história da comunidade; além de socializar os conhecimentos adquiridos na universidade com a comunidade.

Dessa forma, ao discutir sobre uma possível programação da rádio, foram apresentados diversos formatos radiofônicos, a exemplo de entrevistas, reportagens e notas, ao mesmo tempo em que se mostrava que o rádio pode incluir em sua programação, poesias, música, quadros de histórias infantis, de culinária e de saúde. A ideia era que a programação trouxesse diferentes temáticas e várias vozes, e ainda estimulasse a interatividade, em um cenário de convergência midiática, no qual as mídias tradicionais se fundem às digitais.

As experiências com o uso das redes sociais, como Facebook e de ferramentas, como o Facebook Live, durante a veiculação de um programa de rádio acenam para a incorporação, também pela rádio comunitária, do que Kischinhevsky (2012, p. 2) define como um rádio expandido, ou seja, um rádio que com seus novos serviços e canais de distribuição "transborda para mídias sociais e microblogs, que potencializam seu alcance e a circulação de seus conteúdos". Um rádio, deste modo, que extrapola os limites do som das ondas sonoras para apropriar-se de outras linguagens e suportes.

O uso de redes sociais e de ferramentas, como o Facebook Live, são iniciativas, no sentido de minimizar o problema enfrentado pelas rádios comunitárias, com relação a pequena área de cobertura, definida por lei. Outra estratégia adotada nesse cenário adaptativo de convergência midiática é a utilização do aplicativo Whatsapp, na intenção de promover uma maior interatividade entre o ouvinte e a rádio comunitária. $\mathrm{O}$ aplicativo pode ser usado de diversas formas pela comunidade indígena. 


\section{Considerações finais}

O Nordeste brasileiro ainda possui um cenário comunicacional complexo, o que impacta diretamente na criação e no funcionamento das rádios comunitárias. Os grandes conglomerados midiáticos encontram-se nas mãos de poucas famílias e a sobrevivência de uma mídia contra hegemônica é ameaçada por perseguições e fechamentos de rádios ainda não legalizadas. Para acentuar o problema, uma parte dos canais de rádios comunitárias têm sido apropriados por políticos, o que Lima \& Lopes (2008) convencionam como coronelismo eletrônico de nova geração. No caso dos indígenas, além de problemas comuns a outros setores, eles ainda têm na legislação de RadCom alguns obstáculos específicos, como já destacamos anteriormente.

Nessa quebra de braço um dos caminhos que se acena para a existência e sobrevivência de uma mídia contra hegemônica nas comunidades indígenas são as rádios virtuais comunitárias, que difundem suas mensagens pela Internet, existindo, portanto, no ciberespaço. Essa modalidade de rádio comunitária está ligada a grupos ou comunidades constituídas a partir da afinidade de interesses e/ou de vivências de problemáticas em comum, tais como os de fundo linguístico, étnico, relações de gênero (PERUZZO, 2010).

A existência no ciberespaço propicia também, que por meio de experiências com o uso das redes sociais, como Facebook e de ferramentas como o Facebook Live, o que se denomina "rádio expandido" (KISCHINHEVSKY, 2012), a rádio comunitária possa transpor o espaço geográfico dos locais onde funciona levando as potencialidades e os problemas da comunidade para além de Pernambuco e até do Brasil.

Diante desse panorama, a criação de uma rádio comunitária na web, organizada e gerenciada pelo povo Truká se acena como uma possibilidade de abertura de um espaço mais democrático e plural, que envolve os indígenas, não somente como receptores de mensagens, mas como protagonistas de um processo de comunicação, reunindo a produção de seus próprios conteúdos, a gestão dos meios de comunicação e uma alternativa de maior visibilidade do povo.

Ao ser partícipe da comunicação, a comunidade tem a possibilidade de ressignificar uma realidade midiática construída unilateralmente pela mídia, que insiste em reforçar a criminalização dos indígenas, esquecendo de pluralizar as potencialidades dos diversos povos.

\section{Referências}

BARBOSA FILHO, André. Gêneros radiofônicos: os formatos e os programas em áudio. São Paulo: Paulinas, 2003. 
JENKINS, Henry. Cultura da convergência. 2. ed. São Paulo: Aleph, 2009.

KISCHINHEVSKY, Marcelo. Radiojornalismo comunitário em mídias sociais e microblogs: circulação de conteúdos publicados no portal RadioTube. In: Estudos em Jornalismo e Mídia, Santa Catarina: Universidade Federal de Santa Catarina, jan-jun. 2012.

LACERDA, Rosane Freire. Radiodifusão Sonora Comunitária em Terras Indígenas: os obstáculos da colonialidade na legislação de RadCom. In: José Geraldo de Sousa Júnior; Murilo César Ramos; Elen Geraldes; Fernando Oliveira Paulino; Janara Sousa; Helga Martins de Paula; Talita Rampin; Vanessa Negrini. (Org.). O Direito Achado na Rua - Introdução Crítica ao Direito à Comunicação e à Informação.

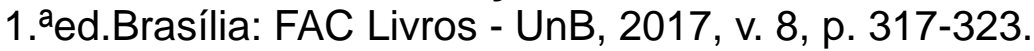

\section{LEMOS, A.; LÉVY, P. O futuro da Internet: em direção a uma ciberdemocracia} planetária. São Paulo: Paulus, 2010.

LIMA, Venício A. de. LOPES; Cristiano Aguiar. Rádios comunitárias: coronelismo eletrônico de novo tipo (1999-2004). In: ROLIM, Renata (org.). Rádio, movimentos sociais e direito à comunicação. Recife: Oito de Março Gráfica e Editora, 2008.

MAGALHÃES, Caio; NUNES, Márcia. Comunicação comunitária como estratégia política na mídia convencional: um estudo de caso do Meu Bairro na TV. In: Anais do XXIII Encontro Anual da COMPOS, Pará: maio de 2014.

MINISTÉRIO DA CIÊNCIA, TECNOLOGIA, INOVAÇÕES E COMUNICAÇÕES. Rádios comunitárias: coronelismo eletrônico de novo tipo (1999-2004). Disponível em:

<http://www.mctic.gov.br/mctic/opencms/comunicacao/SERAD/radiofusao/detalhe_te ma/radiodifusao_comunitaria.html>. Acesso em: 01 de dezembro de 2017.

NUNES, Márcia Vidal. Rádio e Política: do microfone ao palanque - os radialistas políticos em Fortaleza. Tese (Doutorado em Comunicação Social), Fortaleza: Universidade Federal do Ceará, 1998.

ORTRIWANO, Gisela Swetlana. A Informação no Rádio: os grupos de poder e a determinação dos conteúdos. 3. ed. São Paulo: Summus, 1985.

PERUZZO, Cicilia. Mídia comunitária. Revista Comunicação e Sociedade. n. 32. São Bernardo do Campo: UMESP, 1998b.

Comunicação nos movimentos populares: a participação na construção da cidadania. 3 ed. Petrópolis: Vozes, 2004.

. Rádio comunitária, educomunicação e desenvolvimento local. In: PAIVA, R. (Org.). O retorno da comunidade. Rio de Janeiro: Mauad, 2007. p. 69-94.

. Conceitos de Comunicação popular, alternativa e comunitária revisitados. 
Reelaborações no setor. Palabra Clave. Bogotá: Facultad de Comunicación, Universidad de La Sabana, dez. 2008.

Aproximações entre a comunicação popular e comunitária e a imprensa alternativa no Brasil na era do ciberespaço. Revista Galáxia. São Paulo: PósGraduação em Comunicação e Semiótica da Pontifícia Universidade Católica, jun. 2009a.

. Movimentos sociais, cidadania e o direito à comunicação comunitária nas políticas públicas. Revista Fronteiras - Estudos midiáticos. São Leopoldo (RS): Unisinos, jan-abr 2009b.

. Rádios Comunitárias no Brasil: da desobediência civil e particularidades às propostas aprovadas na CONFECOM. In: Anais do XIX Encontro Anual da COMPOS, Rio de Janeiro: maio de 2010.

ROCHA, Ana Luísa Carvalho da Rocha e ECKERT, Cornélia. "Etnografia: saberes e práticas." In: Ciências Humanas: pesquisa e método, Porto Alegre: Editora da universidade, 2008.

SILVA, Everaldo Fernandes da; SILVA, J. B. Experiência e processos formativos na rede indígena de Pernambuco: $O$ Pibid diversidade e as leituras decoloniais. Revista Interritórios, v. 1, 2015, p. 141-156. 